\title{
NADZOR NAD ZARAZNIM BOLESTIMA U FEDERACIJI BOSNE I HERCEGOVINIE
}

\author{
Vesna Pehar, Ivan Vasilj, Slavica Mikulić \\ Sveučilište u Mostaru, Fakultet zdravstvenih studija
}

Rad je primljen: 19.2.2015.

Rad je revidiran: 11.3.2015.

Rad je prihvaćen: 6.4.2015.

\section{SAŽETAK}

UVOD: Nadzor zaraznih bolesti predstavlja važnu mjeru javnozdravstvene politike i prakse u zaštiti zdravlja stanovništva. Nadzor podrazumijeva prikupljanje, analizu i diseminaciju podataka o pojavi i kretanju zaraznih bolesti. Temelji se na zakonskoj obvezi prijavljivanja zaraznih bolesti. Cilj rada je utvrditi učestalost zaraznih bolesti temeljem prijava zaraznih bolesti koje podliježu obveznoj prijavi kao i epidemije zaraznih bolesti sukladno (Zakonu o zaštiti pučanstva od zaraznih bolesti, Sl. n. FBiH br. 29/05) u razdoblju od 1. siječnja 2011. do 31. prosinca 2012. godine.

MATERIJALI I METODE: Retrospektivno istraživanje koje je sačinjeno uvidom u Zdravstveno statistički godišnjak FBiH 2011. i 2012. godine Zavoda za javno zdravstvo FBiH. Registrirane oboljele od zaraznih i parazitarnih bolesti obradili smo prema: broju oboljelih za zadano razdoblje, županijama, spolu, dobu, vodećih deset zaraznih bolesti i epidemije zaraznih bolesti prema putu prijenosa.

REZULTATI: Morbiditet zaraznih bolesti u 2012. g. manji je u odnosu na 2011. g. Najveći udio čine respiratorne zarazne bolesti s manjim Mb gripe u odnosu na prethodnu sezonu. Tuberkuloza i dalje zauzima visoko peto mjesto u 2011. godini i šesto mjesto u 2012. godini. Antropozoonoze u 2012. godini imaju manju stopu obolijevanja u odnosu na 2011., ali s većim udjelom u ukupnom broju registriranih zaraznih bolesti u odnosu na prethodnu godinu. Parazitarne zarazne bolesti u 2012. g., imaju nešto veću stopu obolijevanja od one registrirane u 2011. godini.

ZAKLJUČAK: Sprječavanje i suzbijanje zaraznih bolesti predstavlja javnozdravstveni prioritet u Europi. U suradnji s drugim zdravstvenim profilima stručnjaci sanitarnog inženjerstva trebaju uočavati, definirati i sanirati čimbenike okoline koji mogu štetno djelovati na zdravlje pojedinca i širu zajednicu, te provoditi opće i ciljano zdravstveno prosvjećivanje stanovništva poradi unapređivanja $z$ dravlja šire populacije.

Ključne riječi: zarazne bolesti, morbiditet, epidemiološki nadzor, preventivne mjere, zakoni i propisi

Osoba za razmjenu informacija:

Prof.dr.sc. Ivan Vasilj

Email: ivanvasilj@net.hr

\section{UVOD}

Stoljećima su čovječanstvom harale epidemije kuge, kolere, pjegavca, velikih boginja i gripe. Globalno širenje zaraznih bolesti započelo je sa španjolskim osvajačima koji su u novootkrivene zemlje donijeli velike boginje, a preuzeli sifilis. Velike epidemije pojavljuju se sve do današnjih dana (1).

Do polovice 19. stoljeća zarazne su akutne bolesti harale cijelim svijetom i desetkovale stanovništvo. Tada su svojim otkrićem velikani mikrobiologije Louis Pasteur i Robert Koch utrli put saznanju da su zarazne klice uzročnici zaraznih bolesti i da se izbijanje tih bolesti može spriječiti cijepljenjem. Time je počelo suzbijanje velikih zaraznih epidemija, što je bio jedan od razloga naglom porastu broja stanovnika. Skoro istovremeno shvatilo se značenje uređenja javnih sanitarnih uređaja, što je smanjilo mogućnost epidemijskog širenja zaraznih bolesti, najviše crijevnih zaraza. Sljedeći veliki korak bila je mogućnost liječenja zaraznih bolesti zahvaljujući Flemingovom otkriću penicilina u prvoj polovini 20. stoljeća, čime 
počinje era antibiotika. Ipak, s ta tri koraka - masovnim cijepljenjem, podizanjem higijensko-sanitarnog zdravstvenog standarda, antimikrobnim lijekovima - nije došao kraj zaraznim bolestima (2).

Cilj ovog rada je utvrditi učestalost zaraznih bolesti temeljem prijava zaraznih bolesti koje podliježu obveznoj prijavi kao i epidemije zaraznih bolesti sukladno (Zakonu o zaštiti pučanstva od zaraznih bolesti, Sl. n. FBiH br. 29/05) u razdoblju od 1. siječnja 2011. do 31. prosinca 2012. godine.

\section{ISPITANICI I METODE}

Provedeno je retrospektivno istraživanje uvidom u Zdravstveno statistički godišnjak 2011. i 2012. godine Federacije Bosne i Hercegovine $(7,8)$. Prikupljene podatke a registrirane oboljele od zaraznih i parazitarnih bolesti obradili smo prema broju oboljelih za razdoblje od 1. siječnja 2011. do 31. prosinca 2012. godine, županijama, spolu, dobi, vodećih deset zaraznih bolesti, epidemije zaraznih bolesti prema putu prijenosa

\section{Statistička obradba podataka}

Za statističku analizu dobivenih podataka korišten je programski sustav Microsoft Excell (inačica 11. Microsoft Corporation, Redmond, WA, SAD). Podaci su prikazani kao stope morbiditeta na 100000 stanovnika.

\section{REZULTATI}

Na temelju važećih zakonskih propisa, stanje zaraznih bolesti u FBiH se kontinuirano prati stalnim središnjim nadzorom, usmjeravanjem i koordinacijom mjera praćenja, sprječavanja i suzbijanja kroz stručno i funkcionalno povezivanje svih dijelova zdravstvenog sustava, od primarne do bolničke zaštite (4).

Tijekom 2011. i 2012. godine prijavljeno je 143.609 oboljelih od zaraznih bolesti, od čega je $62 \%$ oboljelih u 2011. godini i 38\% u 2012. godini. Ukupan broj prijavljenih slučajeva zaraznih bolesti u 2012. godini u odnosu na 2011. godinu je manji što se objašnjava manjim brojem registriranih oboljelih od gripe uključujući i bolesti slične gripi. Znatno veći $\mathrm{Mb}$ (s gripom) registriran je u 2011. godini čak 3837,49/100 000. (Slika 1.)

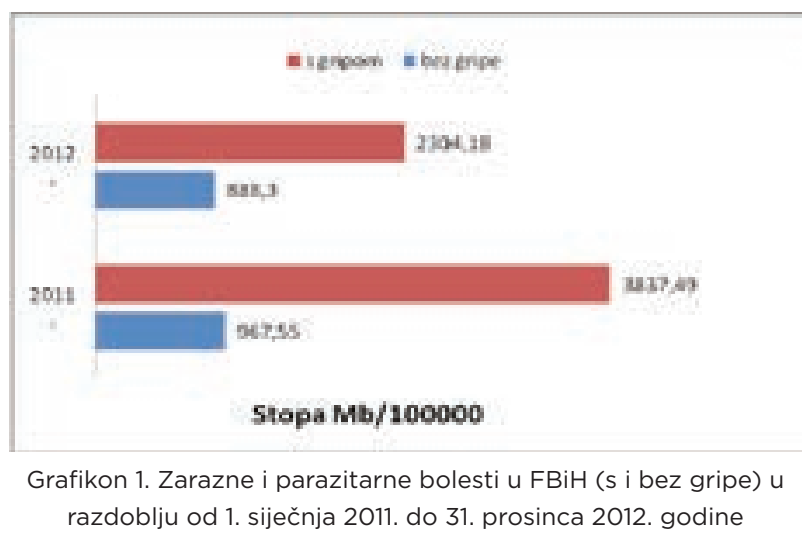

Broj registriranih oboljelih od zaraznih bolesti razlikuje se po županijama (Tablica 1.) te se morbiditet Mb kreće u rasponu od 13065,18/100 000 u Sarajevskoj županiji do 336,73/100 000 u Hercegbosanskoj županiji. Morbiditet zaraznih bolesti u 2012. godini (Tablica 2.) u većini županija manji je u odnosu na 2011. Godini (Tablica 3.) što je rezultat manjeg broja registriranih slučajeva gripe/uključivo i bolesti slične gripi.

Tablica 1. Zarazne i parazitarne bolesti (s gripom) $u$ razdoblju od 1. siječnja 2011. do 31. prosinca 2012. godine po županijama

\begin{tabular}{crrrr}
\hline \multirow{2}{*}{ Županija } & \multicolumn{2}{c}{2011.} & \multicolumn{2}{c}{2012.} \\
\cline { 2 - 5 } & $\begin{array}{c}\text { Broj } \\
\text { oboljelih }\end{array}$ & Mb/100000 & $\begin{array}{c}\text { Broj } \\
\text { oboljelih }\end{array}$ & Mb/100000 \\
\hline Unsko-sanska & 5118 & 17778,10 & 4765 & 1655,17 \\
\hline
\end{tabular}

Tablica 2. Zarazne i parazitarne bolesti (s gripom) $u$ razdoblju od 1. siječnja 2011. do 31. prosinca 2012. godine po županijama

\begin{tabular}{|c|c|c|c|c|}
\hline \multirow[b]{2}{*}{ Županija } & \multicolumn{2}{|c|}{2011.} & \multicolumn{2}{|c|}{2012.} \\
\hline & $\begin{array}{c}\text { Broj } \\
\text { obolielih }\end{array}$ & $\mathrm{Mb} / 100000$ & $\begin{array}{c}\text { Broi } \\
\text { obolielih }\end{array}$ & $\mathrm{Mb} / 100000$ \\
\hline Unsko-sanska & 5118 & 17778,10 & 4765 & 1655,17 \\
\hline Posavska & 416 & 1050,90 & 222 & 564,78 \\
\hline Tuzlanska & 9424 & 1888,74 & 6078 & 1217,79 \\
\hline Zeničko-dobojska & 11965 & 2992,33 & 6137 & 1535,73 \\
\hline Bosansko-podrinjska & 927 & 2824,67 & 505 & 1545,52 \\
\hline Srednje-bosanska & 6725 & 2647,61 & 2173 & 856,89 \\
\hline $\begin{array}{l}\text { Hercegovačko- } \\
\text { neretvanska }\end{array}$ & 10748 & 4778,97 & 2264 & 1007,28 \\
\hline Zapadnohercegovačka & 4705 & 5779,10 & 2023 & 2482,60 \\
\hline Sarajevska & 38784 & 8839,52 & 57584 & 13065,18 \\
\hline Hercegbosanska & 919 & 1150,49 & 291 & 336,73 \\
\hline
\end{tabular}


Tablica 2. Deset vodećih zaraznih bolesti u FBiH u 2012. $g$.

\begin{tabular}{clcc}
\hline \multicolumn{4}{c}{ 2012. godina } \\
\hline Rang & Bolest & $\begin{array}{c}\text { Broj registriranih } \\
\text { slučajeva }\end{array}$ & Mb/100 000 \\
\hline 1. & ILl/gripa & 33107 & 1415,87 \\
2. & Varicellae & 8107 & 346,71 \\
3. & Enterocolitis acuta & 5113 & 218,66 \\
4. & Parotitis epidemica & 1989 & 85,07 \\
5. & Scabies & 864 & 36,96 \\
6. & TBC resp. Sustava & 828 & 35,42 \\
7. & Angina streptococcica & 722 & 30,87 \\
8. & Toxiinfecio Alimentaris & 645 & 27,58 \\
9. & Scarlatina & 416 & 17,79 \\
10. & Herpes zoster & 414 & 17,70 \\
\hline
\end{tabular}

Tablica 3. Deset vodećih zaraznih bolesti u FBiH u 2011.g.

\begin{tabular}{clcc}
\hline \multicolumn{3}{c}{ 2011. godina } \\
\hline Rang & Bolest & $\begin{array}{c}\text { Broj registriranih } \\
\text { slučajeva }\end{array}$ & Mb/100 000 \\
\hline 1. & ILl/gripa & 67107 & 2869,94 \\
2. & Varicellae & 6733 & 287,94 \\
3. & Parotitis epidemica & 5913 & 252,87 \\
4. & Enterocolitis acuta & 4341 & 185,65 \\
5. & TBC resp. Sustava & 862 & 36,86 \\
6. & Angina streptococcica & 843 & 36,05 \\
7. & Scabies & 832 & 35,58 \\
8. & Toxiinfecio Alimentaris & 685 & 29,30 \\
9. & Herpes zoster & 391 & 16,72 \\
10. & Salmonellosis & 389 & 16,64 \\
\hline
\end{tabular}

Među vodećim zaraznim bolestima i u 2011. $(63,34 \%)$ i 2012 . $(76,17 \%)$ godini na visokom prvom mjestu je ILI/gripa, zatim varicella u obje godine s 8107 (15,53\%) registriranih slučajeva u 2012.g. i 6733 (7,64\%) u 2011.g. Na trećem mjestu je parotitis epidemica, dok je u 2012. na četvrtom mjestu, TBC respiratornog sustava je na petom mjestu u 2012. g. iako sa manjom stopom obolijevanja u odnosu na prethodne godine, a u 2011. na šestom mjestu. U 2012.g scarlatina ponovno među deset vodećih zaraznih bolesti.

\section{RASPRAVA}

Premda je značenje zaraznih bolesti u razvijenim zemljama umanjeno njihov je globalni značaj i dalje velik. Ubrzo je nestao početni zanos stručnjaka iz 1960-ih i 1970-ih godina, kako je efikasnim općim i specifičnim mjerama globalno strategijski riješen problem zaraznih bolesti. Razlog tome je porast smrtnosti radi pojave AIDS-a 1980-ih. U porastu je smrtnost i zbog septikemija i infekcija dišnog sustava. Osim toga, neke zarazne bolesti pokazuju svoje novo "staro « lice, poput difterije. Tako je u bivšim zemljama Sovjetskog Saveza 90-ih došlo do pojave velike epidemije difterije s visokom stopom smrtnosti. Do 1996. godine prijavljeno je 125000 bolesnika, od kojih je 4000 umrlo. U isto vrijeme javlja se u Južnoj Americi epidemija kolere s preko milijun oboljelih. Pertusis postaje ozbiljan problem u Nizozemskoj usprkos provođenju imunizacije (9). Stoga su zarazne bolesti i dalje vodeći uzrok smrti širom svijeta (33\%), ispred smrti izazvanih bolestima cirkulatornog sustava (29\%) ili karcinoma (12\%) (2). Live Wordmeters bilježi podatke svjetske statistike o broju stanovnika, vladi i ekonomiji, društvu, medijima, okolini, energiji, vodi, zdravlju itd., tako je trenutno u 2014. godini umrlo od zaraznih bolesti 6.946.847 ljudi u svijetu (10).

S obzirom na smrtnost u globalnom smislu danas su u svijetu najznačajnije akutne infekcije donjeg dišnog sustava, tuberkuloza, diarealne bolesti, HIV/ AIDS, malarija, ospice, hepatitis B, pertusis, neonatalni tetanus, hemoragijske groznice i drugo (11).

U Bosni i Hercegovini je smrtnost od zaraznih bolesti vrlo niska zahvaljujući poboljšanju općih uvjeta života, te razvoju medicine i zdravstva.

Bez obzira na postignute uspjehe u suzbijanju i prevenciji zaraznih bolesti one i dalje u globalnom smislu ostaju značajne za čovjeka. I danas čak $1 / 3$ smrti nastaje kao posljedica zaraznih bolesti (12).

Ako bi socijalno-ekonomsko-zdravstveni standard ostao kao i danas, u nadolazećim desetljećima stanje sa zaraznim bolestima bilo bi sve povoljnije. No, ako bi preventivno-sanitarno-higijenske prilike postale nepovoljnije, stanje sa zaraznim bolestima počelo bi se vraćati u prošlost, u prilike kao što su u nerazvijenim siromašnim zemljama. Osnovni su preduvjet da do toga ne dođe solidni gospodarski temelji i zadovoljavajuća opća i zdravstvena kultura stanovništva. 


\section{ZAKLJUČCI}

Morbiditet zaraznih bolesti u 2012. g. manji je u odnosu na 2011. godinu. Najveći udio čine respiratorne zarazne bolesti s manjim $\mathrm{Mb}$ gripe $\mathrm{u}$ odnosu na prethodnu sezonu, tuberkuloza i dalje zauzima visoko peto mjesto u 2011. godini i šesto mjesto u 2012. godini s morbiditetom $35,42 / 100$ 000, ali sa smanjenom stopom obolijevanja u odnosu na 2011. godinu (36,86/100 000). Antropozoonoze u 2012. godini imaju manju stopu obolijevanja, 4,61/100 $000 \mathrm{u}$ odnosu na 2011. (5,55/100 000), ali s većim udjelom u ukupnom broju registriranih zaraznih bolesti $(0,20 \%) \mathrm{u}$ odnosu na prethodnu godinu (0,14\%). Parazitarne zarazne bolesti u 2012. g., s Mb 38,78/100 000 imaju nešto veću stopu obolijevanja od one registrirane u 2011. godini (37,24/100 000), Svrab s 864 registrirana slučaja bilježi porast u odnosu na 2011.godinu (832 slučaja). Skupina ostalih zaraznih bolesti, s 896 registriranih slučajeva u 2012. godini bilježi neznatno povećanje u odnosu na 2011. godinu (889 registriranih slučajeva).

\section{LITERATURA}

1. Ropac D., Treba li se još uvijek bojati zaraznih bolesti? Internet: Dostupno: http://www.samoborskiglasnik.net/kolumne.asp?sif $=1763 \&$ ti$\mathrm{p}=123$ \&tempg $=2012$, pristupljeno (9. svibanj 2014.)

2. Ružička I., Spriječiti povratak u prošlost, Narodni zdravstveni list, Nastavni zavod za javno zdravstvo Primorsko-goranske županije, godina LV, br. 646-647,/2013. studeni/prosinac

3. Pahor Đ., Opasnost je svuda oko nas, Narodni zdravstveni list, Nastavni zavod za javno zdravstvo Primorsko-goranske županije, godina LV, br. $646-647, / 2013$. studeni/prosinac
4. Epidemiološki nadzor nad zaraznim bolestima u FBiH, Bilten XX br. 31., URL: http:// www.zzjzfbih.ba/wp-content/uploads/2013/04/ Bilten-br-31-Epidemiolos\%CC\%8Cki-nadzor-nad-zaraznim-bolestima-u-FBiH-2012.pdf, pristupljeno (10. svibanj 2014.)

5. Plan razvoja javnog zdravstva za razdoblje 2011. - 2015. („Narodne novine“, broj 49/11), Hrvatskog zavoda za javno zdravstvo, Internet: http:// www.propisi.hr/print.php?id=11035, pristupljeno (12. lipanj 2014.)

6. Zakon o hrani, Službeni glasnik $\mathrm{BiH}$, br.50/04, Internet: http://www.msb.gov.ba/dokumenti/7Zakon_o_hrani.pdf, pristupljeno (28.srpanj 2014.)

7. Zdravstveno statistički godišnjak Federacije Bosne i Hercegovine, Zavod za javno zdravstvo FBiH, Meligraf Sarajevo, Godina X, broj X, str 152-156.

8. Zdravstveno statistički godišnjak Federacije Bosne i Hercegovine, Zavod za javno zdravstvo FBiH, Meligraf Sarajevo, Godina XI, broj XI, str 151-155.

9. LeDuce J. World Health Organization strategy for emerging infectious diseases. JAMA 1996;275:318-20.

10. Worldometers - real time world statistics, Internet: http://www.worldometers.info/hr/, pristupljeno (12. lipnja 2014).

11. Murray CJ, Lopez AD. Global mortality, disability and the contribution of risk factors: Global Burden on Disease Study. Lancet, 1997;349:1436-42.

12. Heymann DL, ur. Control of Communicable Diseases Manual, 18th izd. Washington DC: American Public Health Association;2004: 15-6 


\title{
SURVEILLANCE OF INFECTIOUS DISEASES IN THE FEDERATION OF BOSINA AND HERZEGOVINA
}

\author{
Vesna Pehar, Ivan Vasilj, Slavica Mikulić \\ University of Mostar, Faculty of Health Studies
}

\begin{abstract}
INTRODUCTION: Surveillance of infectious diseases is an important precaution in public health policies and practices which protect the health of the population. Surveillance includes the collection, analysis and dissemination of data on the occurrence and movement of infectious diseases, and is based on the legal responsibility to report infectious diseases. The objective of the paper is to determine the prevalence of infectious diseases based on the entries of obligatory registrations of the same disease, as well as outbreaks of infectious diseases in accordance with the Law on Protection of Population from Infectious Diseases.

MATERIALS AND METHODS: A retrospective study composed by examining the Health Statistical Yearbook of the Federation's Public Health Institute in 2011 and 2012. Registered patients suffering from infectious and parasitic diseases were processed according to: the number of patients for each given period, county, sex, age, ten leading infectious diseases and epidemics of infectious diseases, and according to their transmissions.

RESULTS: The morbidity of infectious diseases in 2012 decreased when compared to year 2011. Respiratory infectious diseases take up the largest proportion. Tuberculosis is still situated on the fifth place in 2011 and on the sixth in 2012. Antropozoonoze have a lower rate in 2012 when compared to 2011, and parasitic infectious diseases have a slightly higher rate of illness in 2012, than those same registered in 2011.

CONCLUSION: The prevention and control of infectious diseases is a public health priority in Europe. In collaboration with other health professions, sanitary engineers should perceive, define and remediate the environmental factors which can affect the health of individuals and the wider community, and they should implement health awareness of the individual and the wider population for the sake of improving their health.
\end{abstract}

Key words: infectious diseases, morbidity, epidemiological surveillance, preventive measures, laws and regulations.

Correspondence:

Ivan Vasilj, PhD

E-mail: ivanvasilj@net.hr 